\title{
Germinação de uredósporos de Puccinia kuehnii submetidos a diferentes temperaturas e tempos de incubação
}

\author{
Claudinei Antonio Minchio ${ }^{1}$; Marcelo Giovanetti Canteri²; José Antonio Rocha ${ }^{3}$
}

\begin{abstract}
${ }^{1}$ Programa de Pós-graduação em Agronomia, Departamento de Agronomia, Universidade Estadual de Londrina, Rod. Celso Garcia Cid, PR 445, Km 380, Cx. Postal 6001, 86051-990, Londrina, Paraná, Brasil. ²Departamento de Agronomia, Universidade Estadual de Londrina, Londrina, Paraná, Brasil. ${ }^{3}$ Laboratório de Fitopatologia, Universidade Estadual de Londrina, Londrina, Paraná, Brasil.

Autor para correspondência: Claudinei Antonio Minchio (minchio@ibest.com.br)

Data de chegada: 22/10/2010. Aceito para publicação em: 10/10/2011.
\end{abstract}

\section{RESUMO}

Minchio, C. A.; Canteri, M.G.; Rocha, J.A. Germinação de uredósporos de Puccinia kuehnii submetidos a diferentes temperaturas e tempos de incubação. Summa Phytopathologica, v.37, n.4, p.211-214, 2011.

A ferrugem alaranjada, causada por Puccinia kuehnii é atualmente uma das doenças mais importantes da cana-de-açúcar, devido ao potencial de danos às variedades suscetíveis. Este trabalho objetivou avaliar o efeito da temperatura na germinação dos uredósporos. Os uredósporos foram coletados em cultivo comercial de cana-de-açúcar, da variedade SP 891115, no município de Andirá (PR). Após serem retirados das folhas, os uredósporos foram submetidos a separação de impurezas e colocados em solução de água destilada com Tween-20. A suspensão de esporos, foi calibrada com o uso de câmara de Neubauer e plaqueada uma alíquota de $0,1 \mathrm{ml}$ sobre o meio ágar-água (1,5\%). As placas foram colocadas em câmara de germinação do tipo BOD, nas temperaturas: $10,15,20,25$ e $30^{\circ} \mathrm{C}$, em seis períodos de incubação: 1, 3, 6, 12, 18, 24 horas, totalizando 30 tratamentos com 5 repetições. Ao final de cada período, a germinação foi interrompida adicionando-se $0,1 \mathrm{ml}$ de lactofenol. Dividiu-se cada placa em quatro campos e avaliou-se em cada um, 50 esporos. Os dados de porcentagem de germinação foram submetidos à análise de variância em esquema fatorial $5 \times 6$ com desdobramento da interação em polinômios ortogonais. Pelo ajuste de modelo matemático, a germinação máxima ocorreu para o período de $12 \mathrm{~h}$ e à temperatura de $21^{\circ} \mathrm{C}\left(\mathrm{R}^{2}=82 \%\right)$. Para os períodos de incubação, o modelo estimou que na curva de temperatura $20^{\circ} \mathrm{C}$, foram necessárias 14 horas $\left(\mathrm{R}^{2}=65 \%\right)$ para se atingir a germinação máxima.

Palavras-chave adicionais: Epidemiologia, incubação, condições ambientais.

\section{ABSTRACT}

Minchio, C. A.; Canteri, M.G.; Rocha, J.A. Germination of uredospores of Puccinia kuehnii subjected to different temperatures and incubation times. Summa Phytopathologica, v.37, n.4, p.211-214, 2011.

The orange rust caused by Puccinia kuehnii, is currently one of the most important diseases of sugarcane due to the potential damage to susceptible varieties. This study evaluated the effect of temperature on germination of uredospores. Uredospores were collected in the commercial field of sugarcane, variety SP 891115 in the city of Andirá (PR). After being removed from leaves, the uredospores underwent separation of impurities and placed in a solution of distilled water with Tween-20. The spores suspension was calibrated using a Neubauer chamber and plated an aliquot of $0.1 \mathrm{ml}$ on the agar-water $(1.5 \%)$. The plates were placed in BOD, at temperatures: $10,15,20,25$ and $30^{\circ} \mathrm{C}$ in six incubation periods: $1,3,6,12,18,24$ hours, totaling 30 treatments with five replications. At the end of each period, germination was stopped by adding $0.1 \mathrm{ml}$ of lactophenol. Each plate was divided into four fields and 50 spores were assessed in each field. Data on germination percentage were subjected to analysis of variance in a factorial $5 \times 6$ with the unfolding of interaction in orthogonal polynomials. By adjustment of mathematical model, the maximum germination occurred for the period of $12 \mathrm{~h}$ at a temperature of $21^{\circ} \mathrm{C}(\mathrm{R} 2=82 \%)$. For the incubation periods, the model estimated that in the curve of temperature $20^{\circ} \mathrm{C}$ were required 14 hours (R2 $=65 \%)$ to reach maximum germination.

Keywords: Epidemiology, incubation, environmental conditions.

A ferrugem alaranjada da cana-de-açúcar, cujo agente etiológico é o fungo Puccinia kuehnii (W. Krüger) E.J. Butler, é uma doença que está presente em diversas partes do mundo $(5,12,14,16)$, sendo que o seu primeiro relato em continente americano ocorreu na Flórida (E.U.A), no ano de 2007, sendo posteriormente disseminada a outros países produtores como México, El Salvador, Nicarágua, Panamá, Costa Rica, Guatemala, Venezuela e Cuba $(6,14,18,20)$. No Brasil a doença foi diagnosticada em 2009, na região de Araraquara (SP) (3).
A partir da década de 90 a doença causou perdas significativas, quando evidenciou-se na Austrália danos na variedade Q124 (2), da ordem de $24 \%$ (3). Os efeitos mais danosos da doença ocorrem em países onde a produção se concentra em torno de poucas variedades suscetíveis $(3,19)$.

A disseminação do patógeno é feita principalmente pelo vento e também por respingo d'água da chuva a curtas distâncias $(14,17,23)$. O uso de variedades resistentes, controle químico $(3,6,11,12,13,18$, 
24) e controle cultural (12), atualmente são as formas de manejo da ferrugem. No Brasil, as variedades RB 72454, SP 89-1115 e SP 842025 são as mais suscetíveis (3). Apresentando menor severidade, foi relatada a variedade RB 85-5156 e SP 81-3250. Segundo Hoffmann et al. (10) e Censo Varietal (4), estas variedades correspondem a 25,3\% da área brasileira cultivada com cana-de-açúcar.

O genótipo e a idade da planta são fatores importantes para o progresso da ferrugem. A maior sensibilidade da planta à doença está entre os quatro a cinco meses de idade (14), sendo o terço apical da folha o menos atacado.

Avaliando as condições ambientais que favorecem a ferrugem alaranjada, pode-se dizer que a severidade da doença intensifica-se com chuvas, alta umidade relativa do ar e temperatura elevada no verão $(1,16,19,23)$ e alternância de calor e frio no outono (16). A germinação dos uredósporos ocorre dentro do intervalo de 17 a $34^{\circ} \mathrm{C}$, com temperatura ótima de $18^{\circ} \mathrm{C}$ e umidade relativa de $97 \%$ (14). Para ferrugem marron (Puccinia melanocephala Syd. \& P. Syd.), a temperatura ótima para germinação dos uredósporos está em torno de $25^{\circ} \mathrm{C}$, sendo que ocorre germinação numa faixa ampla de 5 a $34^{\circ} \mathrm{C}$. Os uredósporos germinam e formam apressórios na superfície da folha em temperaturas de 5 a $30^{\circ} \mathrm{C}$, sendo o ótimo entre 15 a $30^{\circ} \mathrm{C}(21)$. Segundo Hsieh et al (8), Hsieh \& Fang (9) e Purdy \& Dean (22), para ambos os patógenos, a temperatura ótima está em torno de 22 a $26^{\circ} \mathrm{C}$, ocorrendo germinação num intervalo de temperatura de 10 a $34^{\circ} \mathrm{C}$.

Mantidos a uma temperatura em torno de 5 a $10^{\circ} \mathrm{C}$, os uredósporos permaneceram viáveis por dois meses, perdendo a viabilidade quando em seguida foram expostos a $26^{\circ} \mathrm{C}$. A germinação dos uredósporos ocorreu três horas após serem submetidos a uma temperatura de $26^{\circ} \mathrm{C}(8)$.

Kramer \& Eversmeyer (15) avaliando germinação de $P$. recondita e $P$. graminis observaram que o máximo de crescimento de tubo germinativo de $P$. recondita foi a 10,14 e $22^{\circ} \mathrm{C}$ com 17 horas de incubação. Lise de tubo germinativo foi evidenciado em aproximadamente $2 \%$ a $4 \mathrm{~h}$ em todas as temperaturas testadas, porém, as maiores porcentagens em temperatura acima de $30^{\circ} \mathrm{C}$.

Sendo assim, o presente trabalhou objetivou avaliar o efeito da temperatura de incubação na germinação de uredósporos de P. kuehnii, encontrados no Estado do Paraná.

O ensaio foi realizado no Laboratório de Fitopatologia, da Universidade Estadual de Londrina. Os uredósporos foram coletados na Usina USIBAN, município de Andirá (PR) em cultivo comercial de cana-de-açúcar, da variedade SP 891115 (Coordenadas $23^{\circ} 02^{\prime} 02$ ' S e 50 $11^{\prime} 48^{\prime \prime}$ W), no dia 26/04/2010. Os uredósporos foram removidos das folhas pelo uso de uma escova de dente, transferidos para vasilhame plástico coberto com papel alumínio. Em seguida passaram por peneira de 200 meshes, a fim de proporcionar separação de impurezas. Transferiram-se os esporos para tubo ependorf. Preparou-se a suspensão de esporos $\left(2 \times 10^{5}\right.$ esporos por ml) com o uso de câmara de Neubauer em solução de Tween-20, composta por 1 gotas de Tween-20 para cada litro de água. Plaqueou-se uma alícota de $0,1 \mathrm{ml}$ sobre o meio ágar-água $(1,5 \%)(7)$.

O delineamento experimental foi inteiramente casualizado em esquema fatorial $5 \times 6$, com 5 repetições. As placas, foram colocadas em 5 BODs, reguladas nas temperaturas: $10,15,20,25$ e $30^{\circ} \mathrm{C}$, sendo feitas leituras de germinação de esporos em seis períodos de incubação: 1, 3, 6, 12, 18, 24 horas, sendo que cada placa representou uma repetição. Ao final de cada período de incubação, a germinação foi interrompida com a adição de gotas de lactofenol na superfície do meio com ágar-água.

Com o auxílio de um microscópio ótico, usando o aumento de 100 vezes, dividiu-se cada placa em quatro campos, e contou-se em cada campo 50 esporos, entre germinados e não-germinados, totalizando 200 esporos por placa. Os esporos foram considerados germinados quando o tubo germinativo fossem maiores ou iguais ao seu diâmetro. Os dados de porcentagem de germinação foram submetidos à análise de variância, desdobrando-se os graus de liberdade em polinômios ortogonais até $2^{\circ}$ grau.

Os resultados da análise de variância indicaram que as temperaturas apresentaram efeitos diferentes sobre a germinação dos uredósporos de P. kuehnii no nível de $1 \%$ de probabilidade. $\mathrm{Na}$ análise do efeito dos tempos de incubação na germinação, o teste também foi significativo a $1 \%$.

Nos desdobramentos da análise da interação temperatura e tempo de incubação, os resultados indicaram interação significativa no nível de $1 \%$ de significância, onde os efeitos de temperatura sobre germinação dependem do tempo de incubação e vice-versa.

O modelo matemático que melhor expressou a relação funcional entre a temperatura $(\mathrm{X})$ e porcentagem de germinação $(\mathrm{Y})$ foi $\mathrm{Y}=$ $5,05979+2,014402 \mathrm{X}-0,047758 \mathrm{X}^{2}\left(\mathrm{R}^{2}=64,52 \%, \mathrm{p}<0,001\right) \mathrm{com}$ germinação máxima de $26,3 \%$ verificada na temperatura de $21^{\circ} \mathrm{C}$.

$\mathrm{O}$ modelo matemático que melhor expressou a relação funcional entre o tempo de incubação (X) e porcentagem de germinação (Y) foi $\mathrm{Y}=18,977942+1,227714 \mathrm{X}-0,045430 \mathrm{X}^{2}\left(\mathrm{R}^{2}=79,14 \%, \mathrm{p}<0,001\right) \mathrm{e}$ germinação máxima de 27,3\% verificada em 14 horas de incubação.

Mesmo considerados independentes, os fatores temperatura e tempo de incubação optou-se por um estudo mais detalhado a partir do desdobramento da análise do comportamento de um fator dentro de cada nível do outro fator para se buscar as reais causas da aceitação da hipótese de que não há interação entre os fatores.

Quando os uredósporos foram submetidos a $3 \mathrm{~h}, 12 \mathrm{~h}$ e $24 \mathrm{~h}$ de incubação, a temperatura afetou a porcentagem de germinação. (Tabela 1).

De acordo com o modelo matemático determinou-se as temperaturas onde as germinação foi máxima, nos respectivos tempos de germinação: $3 \mathrm{~h}-21^{\circ} \mathrm{C}$ e $27,9 \%$ de germinação; $12 \mathrm{~h}-21^{\circ} \mathrm{C}$ e $30,8 \%$

Tabela 1 - Modelos matemáticos de regressão ajustado para dados de germinação (Y) de P. kuehnii em função da variável temperatura (X) nos diversos tempos de incubação.

\begin{tabular}{llll}
\hline Tempo de incubação $(\mathbf{h})$ & Modelo para várias temperaturas $\left({ }^{\circ} \mathbf{C}\right)$ & $\mathbf{R}^{2}(\boldsymbol{\%})$ & Pr> Fc \\
\hline 1 & $\mathrm{Y}=12,407+0,383229 \mathrm{X}-0,003686 \mathrm{X}^{2}$ & 40,37 & $0,853^{\mathrm{ns}}$ \\
3 & $\mathrm{Y}=-4,772+3,051771 \mathrm{X}-0,71314 \mathrm{X}^{2}$ & 80,32 & 0,001 \\
6 & $\mathrm{Y}=11,936+1,343257 \mathrm{X}-0,029771 \mathrm{X}^{2}$ & 21,46 & $0,127^{\mathrm{ns}}$ \\
12 & $\mathrm{Y}=-1,032+3,090343 \mathrm{X}-0,075029 \mathrm{X}^{2}$ & 81,96 & 0,001 \\
18 & $\mathrm{Y}=14,384+1,308743 \mathrm{X}-0,034229 \mathrm{X}^{2}$ & 54,66 & $0,080{ }^{\mathrm{ns}}$ \\
24 & $\mathrm{Y}=-3,0+2,967429 \mathrm{X}-0,074286 \mathrm{X}^{2}$ & 89,68 & 0,000 \\
\hline
\end{tabular}


de germinação; $24 \mathrm{~h}-20^{\circ} \mathrm{C}$ e 26,6\% de germinação (Fig.1).

Em todas as temperaturas, a germinação dos uredósporos foi afetada pelo tempo de incubação (Tabela 2).

Os tempos de incubação onde a germinações foi máxima, nas respectivas temperaturas testadas foram: $10^{\circ} \mathrm{C}-14 \mathrm{~h}$ e $23,7 \%$ de germinação; $15^{\circ} \mathrm{C}-13 \mathrm{~h}$ e $28,5 \%$ de germinação; $20^{\circ} \mathrm{C}-14 \mathrm{~h}$ e $32,0 \%$ de germinação; $25^{\circ} \mathrm{C}-14 \mathrm{~h}$ e $26,4 \%$ de germinação e $30^{\circ} \mathrm{C}-10 \mathrm{~h}$ e $26 \%$ de germinação (Fig. 2).

A temperatura ótima de germinação de $P$. kuehnii encontrada foi $21^{\circ} \mathrm{C}$ com período de incubação de $14 \mathrm{~h}$, o que demonstra que o fungo tem preferência por temperatura amena, em contradição ao proposto por Apan et al (1), Magarey (16), Ovalle et al (19) e Seymour et al (23). Os resultados obtidos demonstraram que a temperatura ótima de germinação não foi ampla como as descritas por Hsieh et al (8), Hsieh \& Fang (9) e Purdy \& Dean (22) onde estes sugerem que a germinação ótima ocorre em temperatura variando de 22 a $26^{\circ} \mathrm{C}$, bem como não foi de $25^{\circ} \mathrm{C}$ como observado por Purdy et al $(21)$ ou de $18^{\circ} \mathrm{C}$, como relatado por Infante et al (14). Foi possível observar que em temperaturas inferiores a $17^{\circ}$, também ocorreu germinação dos uredósporos, como observado no ensaio, a $10^{\circ} \mathrm{C}$.

Com $1 \mathrm{~h}$ de incubação foi possível observar a germinação de uredósporos em todas as temperaturas, atingindo o máximo em temperaturas superiores a $20^{\circ} \mathrm{C}$, tempo este mais curto do relatado por Hsieh et al (8), que observaram germinação após $3 \mathrm{~h}$ de incubação.

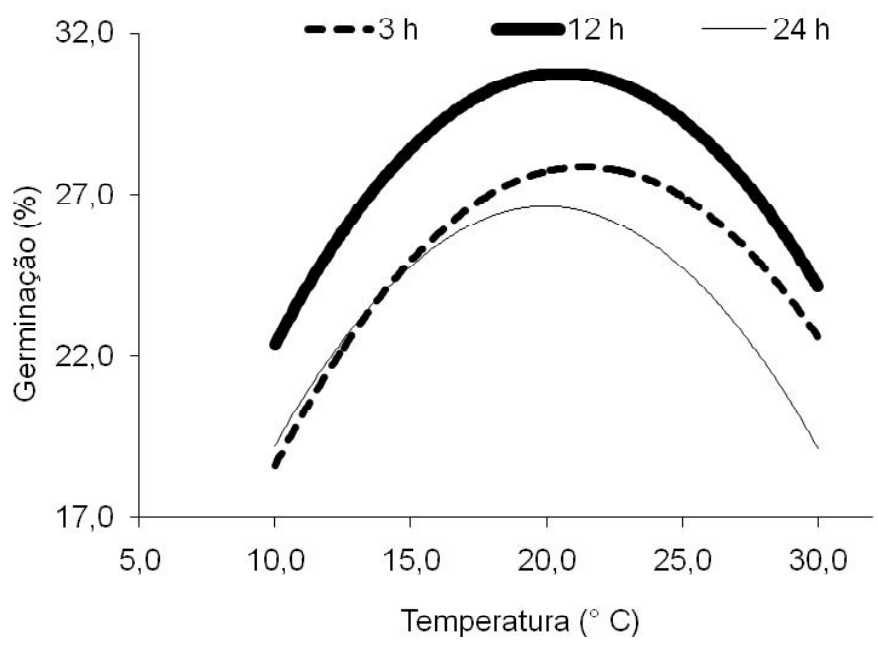

Figura 1. Efeito do tempo de incubação (h) para diversas temperaturas avaliadas $\left({ }^{\circ} \mathrm{C}\right)$ na porcentagem de germinação de uredósporos de Puccinia kuehnii

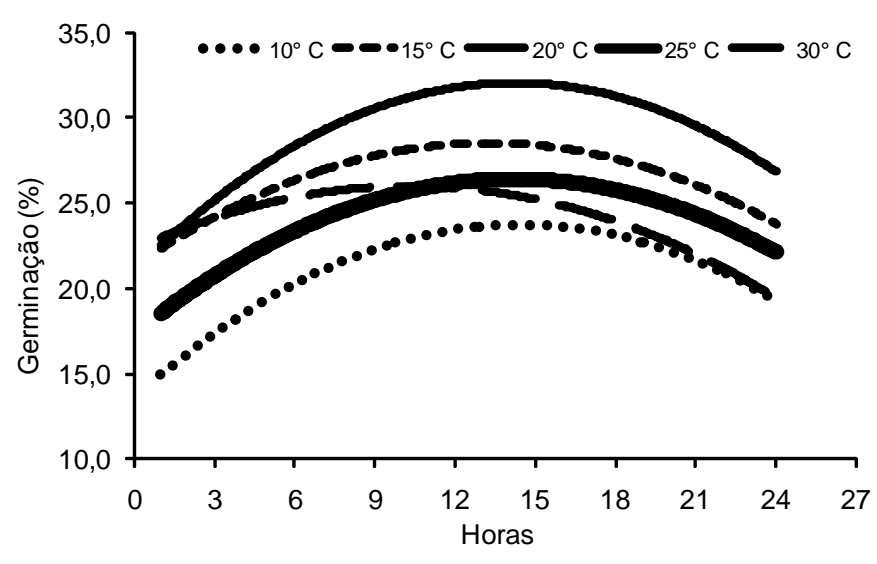

Figura 2. Efeito da temperatura $\left({ }^{\circ} \mathrm{C}\right)$ para os diversos períodos de incubação (h) na porcentagem de germinação de uredósporos de Puccinia kuehnii.

Em condições de temperaturas mais elevadas, em torno de 25 a $30{ }^{\circ} \mathrm{C}$, ocorreu a germinação dos uredósporos, porém em porcentagem inferior à temperatura ideal. O que destaca-se nesse caso é o fato de se atingir maiores índices de germinação até as onze primeiras horas de incubação, diminuindo rapidamente conforme o tempo de incubação aumenta, provavelmente ocasionada pela lise do tubo germinativo proporcionada por estas condições.

Para todas as temperaturas estudadas observou-se que acima de $15 \mathrm{~h}$ de incubação ocorreu redução da germinação, provavelmente decorrente de lise do tubo germinativo dos uredósporos, como sugerido por Kramer \& Eversmeyer (15).

A temperatura ótima de germinação para $P$. kuehnii foi de $21^{\circ} \mathrm{C}$ com período de incubação de $14 \mathrm{~h}$. Os uredósporos obtidos em condições de campo submetidos a estas condições, tiveram germinação máxima de $32 \%$.

\section{REFERÊNCIAS BIBLIOGRÁFICAS}

1. Apan, A.; Held, A.; Phinn, S.; Markley, J. Detecting sugarcane "orange rust" disease usin EO-1 Hyperion hyperspectral imagery. http://eprints.usq.edu.au/2899/1/>. Acesso em: 06 maio 2010.

2. Braithwaite, K.S., Croft, B.J.; Magarey, R.C. Scharaschkin, T. Phylogenetic placement of the sugarcane orange rust pathogen Puccinia kuehnii in a historical and regional context. Australasian Plant Pathology, v.38, n.4, p.380-388, 2009.

3. Brasil. A ferrugem alaranjada (Puccinia kuehnii). Ministério da Agricultura Pecuária e Abastecimento. 2010. Disponível em <http://www.agricultura.gov.br/pls/portal/docs/PAGE/MAPA/ PRINCIPAL/DESTAQUDE>. Acesso em 06 maio 2010.

4. Censo Varietal. Programa de Melhoramento Genético da Cana-de-açúcar. UFScar. Disponível em <http://

Tabela 2. Modelos matemáticos de regressão ajustado para dados de germinação (Y) de P. kuehnii, em função da variável tempo de incubação (X) nas diversas temperaturas avaliadas.

\begin{tabular}{llll}
\hline Temperatura $\left({ }^{\circ} \mathbf{C}\right)$ & Modelo para vários tempos de incubação $(\mathbf{h})$ & $\mathbf{R}^{2}(\%)$ & PR>Fc \\
\hline 10 & $\mathrm{Y}=13,5612+1,4115 \mathrm{X}-0,0489 \mathrm{X}^{2}$ & 95,52 & 0,001 \\
15 & $\mathrm{Y}=21,285311+1,091042 \mathrm{X}-0,041136 \mathrm{X}^{2}$ & 47,54 & 0,006 \\
20 & $\mathrm{Y}=21,0019+1,5525 \mathrm{X}-0,0546 \mathrm{X}^{2}$ & 65,00 & 0,001 \\
25 & $\mathrm{Y}=17,314845+1,275688 \mathrm{X}-0,044838 \mathrm{X}^{2}$ & 65,49 & 0,003 \\
30 & $\mathrm{Y}=22,2811+0,7190 \mathrm{X}-0,0348 \mathrm{X}^{2}$ & 76,48 & 0,022 \\
\hline
\end{tabular}


pmgca.dbv.cca.ufscar.br/html/catal/censovar.php>. Acesso em 11 novembro 2010 .

5. Comstock, J.C.; Sood, S.G.; Glynn, N.C. First report of Puccinia kuehnii, causal aente of orange rust of sugarcane, in the United States and western hemisphere. Plant Disease, v.92, n.1, p.175, jan. 2008 .

6. Flores, R.C.; Loyo, J.R.; Ojeda, R.A.; Rangel, O.C.A. First report of orange rust of sugarcane caused by Puccinia kuehnii in Mexico, El Salvador, and Panama. Plant Disease, v.93, n.12, p.1347, dec. 2009

7. Garcia, E.O.; Casagrande, M.V.; Rago, A.M.; Massola JR. Preservação de urediniósporos de Puccinia melanocephala, agente causal de ferrugem em cana-de-açúcar. Summa Phytopathologica, v. 33 , n. 2 , p. $1-9$, oct. 2006.

8. Hsieh, W.H.; Lee, C.S.; Chan, S.I. Rust disease of sugarcane in Taiwan: the causal organism Puccinia melanocephala Sydow. Taiwan Sugar, v.24, n.5, p.416-410, 1977.

9. Hsieh, W.H.; Fang, J.G. The uredospore production of Puccinia melanocephala and Puccinia kuehnii in sugarcanes. Plant Prot. Bull., v.25, n.4, p.239-244, 1983.

10. Hoffmann, H.P.; Chapola, R.G. Estimativa de perdas com a ferrugem alaranjada. UFSCAR/RIDESA. Disponível em: <http:/ $/ \mathrm{p} \mathrm{m} \mathrm{g} \mathrm{c} \mathrm{a.} \mathrm{d} \mathrm{b} \mathrm{v.} \mathrm{c} \mathrm{c} \mathrm{a.} \mathrm{u} \mathrm{f} \mathrm{s} \mathrm{c} \mathrm{a} \mathrm{r.} \mathrm{b} \mathrm{r} \mathrm{/} \mathrm{d} \mathrm{o} \mathrm{w} \mathrm{/}$ Apresentacao\%E7\%E30\% 20 Ferrugem $\% 20$ Alaranjada.pdf $>$. Acesso em 30 setembro 2010.

11. Hoy, J.W. Leaf rusts: old and new threats to sugarcane. Lousiana Agriculture, v.51, n.2, p.28-29, 2008.

12. Huang, S. Progress of sugarcane disease research in China: Recent developments. Sugarcane Agriculture, v.6, n.4, p.261-265, 2004.

13. Ido, O.T.; Lima-Neto, V.C.; Daros, E.; Possamai, J.C.; Zambon, J.L.C.; Weber, H.; Oliveira, R.A. Incidência e severidade da ferrugem em clones de cana-de-açúcar no Estado do Paraná. Pesquisa Agropecuária Tropical, v.36, n.3, p.159-163, oct. 2006.

14. Infante, D.; Martinez, B.; Gonzalez, E.; Gonzalez, N. Puccinia kuehnii (Kruger) Butler y Puccinia melanocephala H. Sydow y P Sydow. en el cultivo de la caña de azúcar. Revista Protección Vegetal, v.24, n.1, p.22-28, 2009.
15. Kramer, C.L.; Eversmeyer, M.G. Effect of temperature on germination and germ-tube development of Puccinia recondita and $P$. graminis urediniospores. Mycological Research, v. 96, n.8, p.689-693, aug. 1992.

16. Magarey, R.C. Orange rust. In: Root, P.; Bailey, R.A.; Saumtally, A.S. A guide to sugarcane diseases. Rotterdam: CIRAD and ISSCT, 2000. 339p..

17. Mendes, M.A.S.; Freitas, V.M. Espécies de fungos exóticas para a cultura da cana-de-açúcar. EMBRAPA Recursos Genéticos e Biotecnologia. Comunicado Técnico, 128, Brasília, DF, 2005. Disponível em: http://www.cenargen.embrapa.br/publica/trabalhos/ ct2008/cot184_1008.pdf>. Acesso em: 06 maio 2010.

18. Ovalle, W. First report of Puccinia kuehnii, causal agent of orange rust of sugarcane, in Guatemala. Plant Disease, v.92, n.6, p.973, june 2008 .

19. Ovalle, W.; Orozco, H.; Quemé, J.; Melgar, M.; Garcia, S. La roya naranja en Guatemala y estrategias para su manejo. Disponível em: <http://www.sugarjournal.com/articles/active_subs/2009/August2009>. Acesso em 06 maio 2010.

20. Pérez-Vicente, L.; Martín-Triana, E.L.; Barroso, F.; Martínezde-la Parte, E.; Borrás-Hidalgo, O.; Estévez, I.H. Definitive identification of orange rust of sugarcane caused by Puccinia kuehnii in Cuba. New Disease Report, v.20, p.16, oct. 2009.

21. Purdy, L.H.; Liu, L.J.; Dean, J.L. Sugarcane rust, a newly important disease. Plant Disease, v.67, n.11, p.1292-1296, nov. 1983.

22. Purdy, L.H.; Dean, J.L. Rust, an old disease with new importance in sugarcane. Sugar y azúcar, v.78, n.12, p.30-32, 1983.

23. Seymour, C.P.; Miller, J.W.; Schoulties, C.L. Sugarcane rust in the western hemisphere. Plant Pathology Circular, Florida Department of Agriculture and Consumer Service $\mathrm{n}^{\circ} 195$, Florida(E.U.A), 1978. Disponível em: <http:// www.freshfromflorida.com/pi/enpp/pathology/pathcirc/ pp195.pdf>. Acesso em: 06 maio 2010.

24. Sood, S.G.; Comstock, J.C.; Glynn N.C. Leaf whorl inoculation method for screening sugarcane rust sugarcane. Plant Disease, v.93, n.12, p.1335-1340, dec.2009. 